\title{
Article \\ Analysis of Carrier-Based Aircraft Catapult Launching Based on Variable Topology Dynamics
}

\author{
Hu Chen ${ }^{1} \mathbb{1}$, Xingbo Fang ${ }^{1}$ and Hong $\mathrm{Nie}^{1,2, *}$ \\ 1 Key Laboratory of Fundamental Science for National Defense-Advanced Design Technology of Flight Vehicle, \\ Nanjing University of Aeronautics \& Astronautics, Nanjing 210016, China; chenhu14@nuaa.edu.cn (H.C.); \\ fangxingbo@nuaa.edu.cn (X.F.) \\ 2 State Key Laboratory of Mechanics and Control of Mechanical Structures, Nanjing University of Aeronautics \\ and Astronautics, Nanjing 210016, China \\ * Correspondence: hnie@nuaa.edu.cn
}

Citation: Chen, H.; Fang, X.; Nie, H. Analysis of Carrier-Based Aircraft Catapult Launching Based on Variable Topology Dynamics. Appl. Sci. 2021, 11, 9037. https://doi.org/10.3390/ app11199037

Academic Editor: Rosario Pecora

Received: 11 August 2021

Accepted: 24 September 2021

Published: 28 September 2021

Publisher's Note: MDPI stays neutral with regard to jurisdictional claims in published maps and institutional affiliations.

Copyright: (c) 2021 by the authors. Licensee MDPI, Basel, Switzerland. This article is an open access article distributed under the terms and conditions of the Creative Commons Attribution (CC BY) license (https:// creativecommons.org/licenses/by/ $4.0 /)$.

\begin{abstract}
The catapult process of a carrier-based aircraft includes multiple links such as catapult tensioning, separation of the holding rod, dragging and running, separation of the catapult and drag shuttle, and free running. The connection relationships between the front landing gear of the carrier-based aircraft and other related components in each link are different, therefore, it is necessary to adjust the topological relationships of the dynamic model in real time, when solving the catapult dynamics of a carrier-based aircraft. In this paper, a dynamic model of the multibody system of the catapult take-off is established, and a variable topology solution is carried out for the dynamic model by adjusting dynamic augmentation equations; in addition, a dynamic analysis of a carrier-based aircraft catapult and take-off process is carried out. A catapult dynamics model and variable topology solution method were established, which solved the changes at the moment of the restraining rod separation, catapult rod separation, and catapult tackle during the aircraft catapult take-off. After the restraining rod was separated from the front landing gear, the catapult force was transmitted to the rear strut, which instantly increased the load of the rear strut by $238.5 \mathrm{kN}$. In addition, after the carrier-based aircraft reached the end of the catapult's stroke, the catapult rod was separated from the catapult tow shuttle then unloaded, and the load of the rear strut was reduced from $486.2 \mathrm{kN}$ to $-20.3 \mathrm{kN}$. Under the protruding effect of the nose gear, the pitch angle of the carrier-based aircraft increased rapidly from $-0.93^{\circ}$ and reached $0.54^{\circ}$ when the carrier-based aircraft rushed out of the deck.
\end{abstract}

Keywords: carrier-based aircraft; landing gear; catapult take-off; dynamics; variable topology

\section{Introduction}

During the catapult and take-off process of a carrier-based aircraft, the catapult tackle is connected to the front landing gear pillar through the catapult rod, and the restraining rod is connected to the front landing gear antitorsion arm through the locking mechanism. In the initial stage of catapulting, under the action of the thrust of the aircraft engine, the landing gear and holding rod are tightened; after the catapulting starts, the tensioning force of the restraining rod increases with the increase of the catapult force. When the tensioning force of the restraining rod reaches the unlocking threshold of the locking mechanism, the restraining rod is separated from the nose gear, and the catapult tackle drags the nose landing gear of the aircraft to slide forward. When the catapult trolley reaches the end of its catapult stroke, the catapult rod separates from the catapult trolley, and the aircraft continues to accelerate and roll to take off under the thrust of the engine.

Researchers have carried out a lot of research on the catapult and take-off process of carrier-based aircraft. Small [1] explained the advantages of dragging catapult from the front wheel and conducted catapult test research on the E-2A aircraft. Lucas [2] proposed that the shock of the front landing gear when the restraint lever is unlocked causes serious 
fatigue problems to the landing gear structure. Ramsey et al. [3] studied the adaptability of A6-A aircraft and aircraft carrier through experiments. They established mature design standards for the nose landing gear structure of carrier-based aircraft [4], restraining rods and unlocking devices [5,6], and aircraft structure strength [7]. Wang et al. [8] used the intelligent proxy model method to establish a launch model of carrier-based aircraft including the atmosphere, ocean, and ships. Che et al. [9] analyzed the predetermination of the disembarking attitude of the carrier-based aircraft, the design of the guidance law, and other related issues, providing a basis for the evaluation of the safety boundary of the disembarkation. Li et al. [10] studied the influence of the deflection angle of the carrierbased aircraft's elevator on the projection performance of the landing gear, and the influence of the movement of the aircraft carrier on the off-ship attitude of the carrier-based aircraft. Lei [11] establishes a thermodynamic model of the steam catapult, analyzed the catapult process of the carrier- based aircraft with the dynamics model of the carrier-based aircraft, and compared it with the US military test. Wang et al. [11] established a general whole nonlinear model by studying a carrier-based aircraft, and then designed a control scheme for climbing phase. Simulation results show a better control performance with the model and control scheme. Wei et al. [12] and Liu et al. [13] studied the catapult performance of the front landing gear of the carrier-based aircraft theoretically and experimentally, respectively. Yu et al. [14] and Wei et al. [15] studied the structural vibration of the front landing gear at the moment of sudden unloading of the hold bar load and also proposed a solution. Lucas [2] studied the performance parameters of five types of carrier-based aircraft. Results showed that for a given departure speed, some parameters had a critical interval. In this interval, small changes in ejection parameters may lead to great changes in track subsidence after taking off from the deck. Englebry [16] analyzed the impact load on the aircraft of low thrust-weight ratio during ski-jump take-off and described the work of designing and refitting the S-3A aircraft to adapt to the light aircraft carrier. Imhof et al. [17] conducted a simulation analysis on the ski-jump take-off ramp of the aircraft. The research showed that the use of a ski-jump take-off ramp does not affect the take-off performance of the aircraft. Experimental research [18] has also been carried out to test the fast extension performance of the nose landing gear, and results have shown that the load increases rapidly, and the buffer extends rapidly to the maximum stroke when the fast extension starts.

In the current published literature, there are two main types of modeling methods for the launch and take-off dynamics of carrier-based aircraft: the multibody dynamics model established by commercial dynamics software and the single-rigid-body six-degree-offreedom dynamic model with the fuselage of a carrier-based aircraft as the modeling object. There is a lack of dynamic analysis models of variable topology for the entire catapult process, comprising carrier-based aircraft, landing gear, catapult mechanism, and catapult, which is built from the basic theory of multibody system dynamics. Table 1 shows the comparison of modeling methods between the published research and this paper.

Table 1. Comparison of modeling methods between the published research and this paper.

\begin{tabular}{llll}
\hline & \multicolumn{2}{c}{ Current Research } & \multicolumn{1}{c}{ This Paper } \\
\hline & $\bullet \quad \begin{array}{l}\text { multibody dynamics model established } \\
\text { by commercial dynamics software } \\
\text { single-rigid-body six-degree-of-freedom } \\
\text { dynamic model with the fuselage as the } \\
\text { Research } \\
\text { focus }\end{array}$ & $\begin{array}{l}\text { modeling object } \\
\text { lack of dynamic analysis models of } \\
\text { variable topology for the entire catapult } \\
\text { process }\end{array}$ & $\begin{array}{l}\text { evolution of the connection relationship } \\
\text { for catapult take-off, from the basic theory } \\
\text { continuous solution of the separation } \\
\text { process of the restraining rod and the } \\
\text { catapult trolley } \\
\text { a variable topology solution method for } \\
\text { the dynamics analysis }\end{array}$ \\
\hline
\end{tabular}

Starting with the evolution of the connection relationship between the nose gear and peripheral equipment during the catapult process of the carrier-based aircraft, this paper establishes a dynamics model of a multibody system for catapult take-off of a carrier-based 
aircraft. Furthermore, this paper establishes a continuous solution to the separation process of the restraining rod and the catapult trolley by dynamically adjusting the generalized mass matrix, generalized constraint matrix, and generalized force vector of the dynamic model, which provides a variable topology solution method for the dynamic analysis of carrier-based aircraft catapult and take-off. Through analysis by the model, the following conclusions can be drawn: After the restraining rod is separated from the front landing gear, the catapult force is transmitted to the rear strut, which instantly increases the load of the rear strut by $238.5 \mathrm{kN}$. After the aircraft reaches the end of the catapult's stroke, the catapult rod is separated from the catapult tow shuttle, the catapult rod is unloaded, and the load of the rear strut is reduced from $486.2 \mathrm{kN}$ to $-20.3 \mathrm{kN}$. Under the protruding effect of the nose gear, the pitch angle of the carrier aircraft increases rapidly from $-0.93^{\circ}$, and the pitch angle of the aircraft reached $0.54^{\circ}$ when the carrier-based aircraft rushes out of the deck.

\section{Topological Evolution of the Catapult Process of Carrier-Based Aircraft}

During the catapult and take-off process of a carrier-based aircraft, it needs to go through three stages in sequence: restraint tension (Figure 1), drag roll (Figure 2), and free roll (Figure 3). The main difference among the three stages is the difference in the connection status between the front landing gear of the aircraft and the catapult equipment. In the tensioning phase, the front landing gear is connected to the catapult tackle and the restraining rod. In the drag and roll phase, the front landing gear of the aircraft is separated from the restraining rod, and it is accelerated and rolled forward under the traction of the catapult block. When the catapult tackle reaches the end of its catapult stroke, the nose gear is separated from the catapult tackle, and the carrier-based aircraft enters the free-rolling phase until the aircraft rushes out of the aircraft carrier deck.

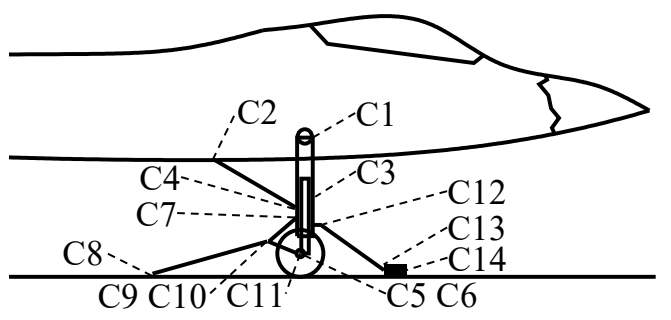

Figure 1. Carrier-based aircraft in the containment and tensioning phase.

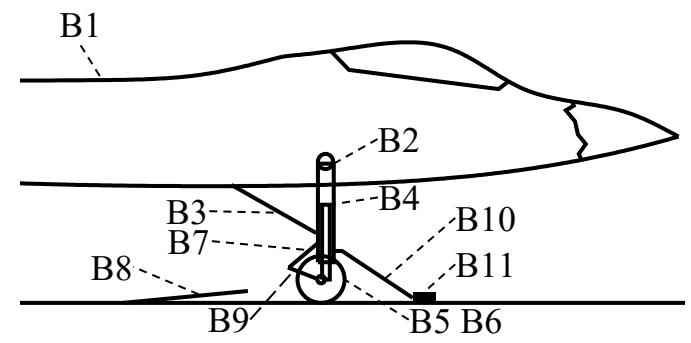

Figure 2. Carrier-based aircraft in the dragging and rolling phase.

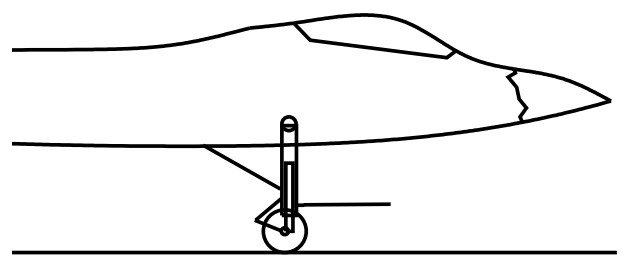

Figure 3. Carrier-based aircraft in the free-rolling phase. 
The names and connection types of the components of the nose gear in Figures 1 and 2 are shown in Table 2. According to the connection relationship between the components of the nose gear and the catapult device during the catapult process of the carrier-based aircraft, the topological relationship between the components of the nose gear and the connection with the catapult equipment can be obtained, shown in Figure 4.

Table 2. Comparison table of some dynamics elements.

\begin{tabular}{cccc}
\hline Numbers & Names & Numbers & Types \\
\hline B0 & Inertial reference frame & C1 & Rotating pair \\
B1 & fuselage & C2 & Spherical pair \\
B2 & Front pillar & C3 & Cylindrical pair \\
B3 & Rear strut & C4 & Spherical pair \\
B4 & Piston rod & C5 & Rotating pair \\
B5 & Left wheel & C6 & Rotating pair \\
B6 & Right wheel & C7 & Rotating pair \\
B7 & Upper anti-twist arm & C8 & Spherical pair \\
B8 & Hold Bar & C9 & Spherical pair \\
B9 & Lower anti-twist arm & C10 & Spherical pair \\
B10 & Catapult lever & C11 & Rotating pair \\
B11 & Catapult tackle & C12 & Rotating pair \\
F1 & Buffer force & C13 & Rotating pair \\
F2 & Left tire force & C14 & Translation pair \\
F3 & Right tire force & & \\
F4 & Catapult force & & \\
\hline
\end{tabular}

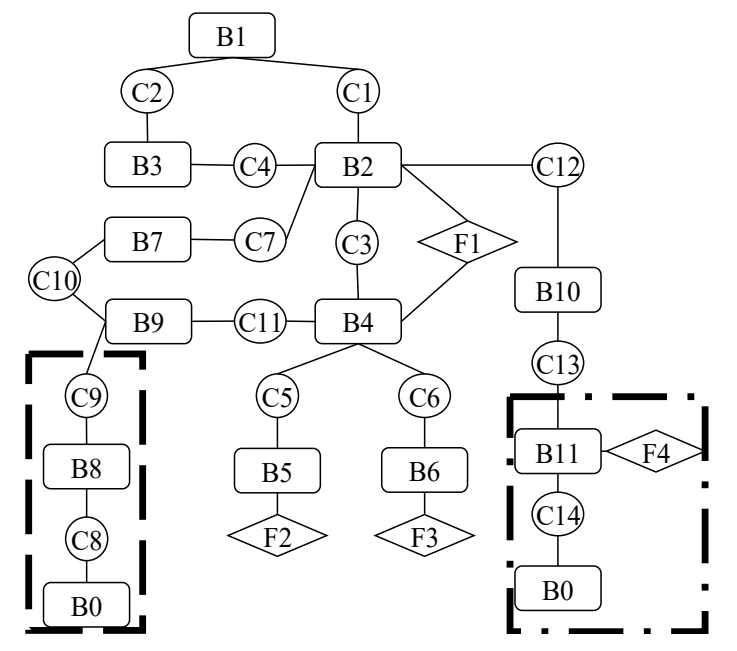

Figure 4. Connection relationships of the front landing structure of a carrier-based aircraft.

The steps for solving the dynamics of the catapult and drag of the carrier-based aircraft are shown in Figure 5. First, start the calculation from the pinned tension state, initialize all dynamic units, and establish dynamic equations according to the topological relationship of the dynamic system. The dynamic equations are solved to obtain the acceleration response of each rigid body unit and the implicit constraint force of each motion sub-unit, and the system state is integrated. Then, judge the state of the system which contains the restraint and tension phase and the sliding phase. It is necessary to further judge the tension of the restraining rod during the tensioning phase. If the tensioning force of the restraining bar does not exceed the design threshold, iterative solution continues. If the tensioning force of the restraining bar exceeds the design load threshold, the dynamic system enters the drag sliding phase; then remove the related dynamic unit of the hold bar in the dashed box in Figure 4, re-establish the dynamic equation and solve it according to the system topology. In the dragging and rolling phase of the aircraft, if the catapult trolley displacement reaches 
the design value of the ejector, the catapult rod is separated from the catapult trolley and the dynamic system enters the free-running state; remove the related dynamic unit of the catapult block in the dotted line frame in Figure 4, re-establish the dynamic equation according to the topological relationship of the dynamic system, and solve it until the carrier aircraft leaves the deck.

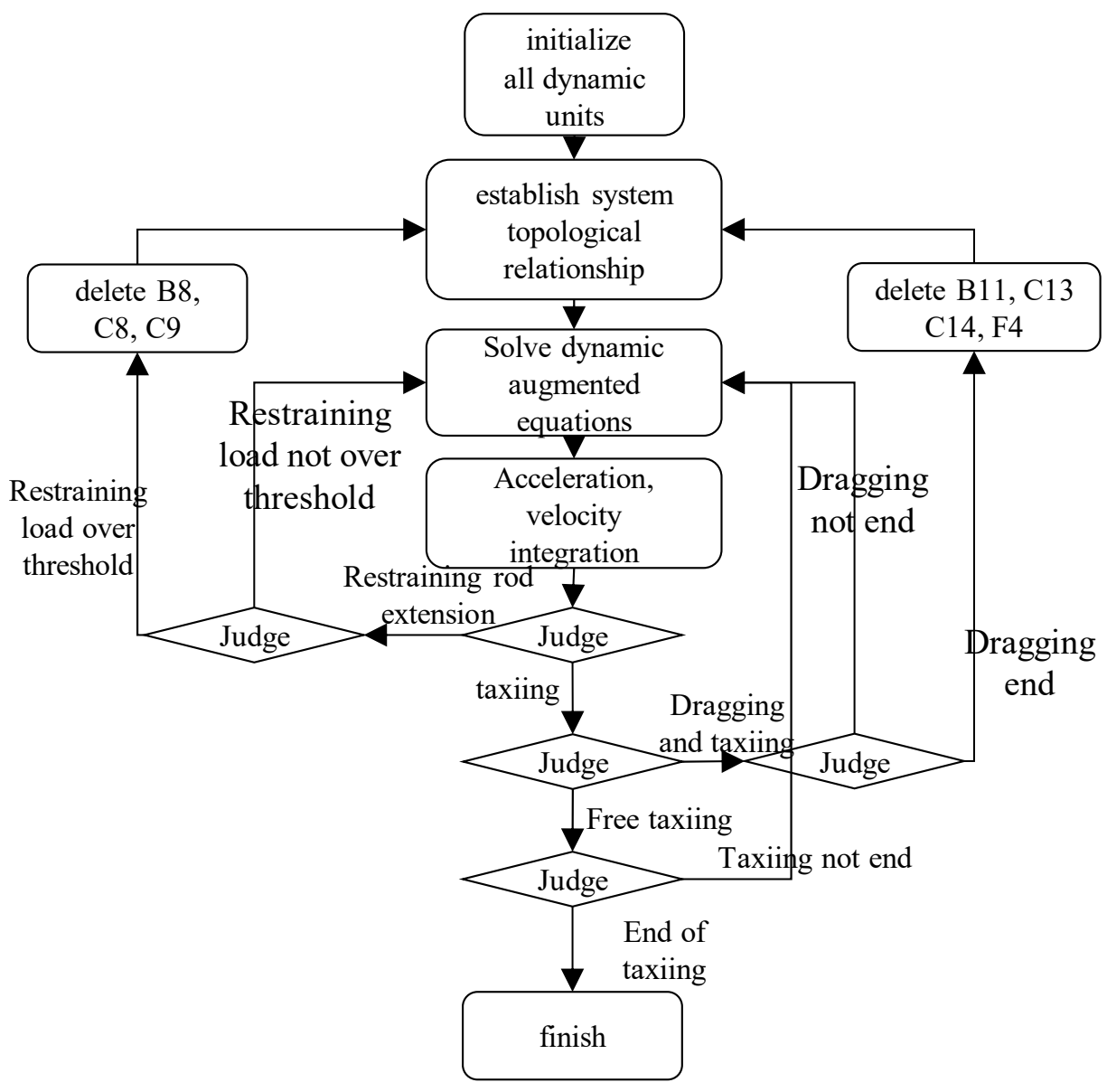

Figure 5. Connection relationships of the front landing structure of a carrier-based aircraft.

\section{Carrier-Based Aircraft Catapult and Take-Off Dynamics Model}

The launch dynamics model of a carrier-based aircraft is established by the Lagrangian method of the first type, which is composed of a rigid body generalized inertial force term, a generalized active force term, and a constraint force term.

\subsection{The Catapult Dynamics Equation of a Carrier-Based Aircraft}

For a multibody system composed of some rigid bodies, the generalized coordinate array of the system can be obtained by combining the generalized coordinate arrays of each rigid body in sequential order. The generalized coordinate array $q$ of the system is defined as follows:

$$
q=\left[\begin{array}{llll}
q^{1 T} & q^{2 T} & \ldots & q^{N T}
\end{array}\right]^{T},
$$

The generalized mass matrix $M$ of the corresponding multibody system is composed of $N$ rigid body mass matrices.

$$
M=\left[\begin{array}{llll}
M^{1} & & & \\
& M^{2} & & \\
& & \ddots & \\
& & & M^{N}
\end{array}\right]
$$


Assuming that $N$ rigid bodies of a multibody system is connected by $n$ kinematics relationships, then the system kinematics constraint matrix $C_{q}$ is divided into $n$ rows in the form of a block matrix. In the $K$ th row, the $K$ th kinematic pair $C_{q i}$ and $C_{q j}$ are filled according to the corresponding rigid body number:

$$
C_{q k}=\left[\begin{array}{llll}
C_{q k}^{i} & \cdots & C_{q k}^{j} & \cdots
\end{array}\right]
$$

The generalized coupled inertial force vector $F_{v}$ of the multibody system is filled by the coupled inertial force of the corresponding rigid body according to the rigid body sequence:

$$
F_{v}=\left[\begin{array}{llll}
F_{v}^{1 T} & F_{v}^{2 T} & \cdots & F_{v}^{N T}
\end{array}\right]^{T},
$$

The generalized active force vector $F_{e}$ of the system is filled by the sum of generalized inertial forces received by the corresponding rigid body in the rigid body sequence:

$$
F_{e}=\left[\begin{array}{llll}
F_{e}^{1 T} & F_{e}^{2 T} & \cdots & F_{e}^{N T}
\end{array}\right],
$$

Therefore, the augmentation method can be used to write the Lagrangian equation of the first type of the system into the following form:

$$
\left[\begin{array}{cc}
M & C_{q}^{T} \\
C_{q} & 0
\end{array}\right]\left[\begin{array}{l}
\ddot{q} \\
\lambda
\end{array}\right]=\left[\begin{array}{c}
F_{e}+F_{v} \\
-\gamma
\end{array}\right]
$$

where: $\lambda$ is the Lagrangian multiplier of the system.

When solving the constraint force of each motion pair in a multibody system, as the system Lagrangian multiplier is multiplied by the constraint matrix, the system constraint reaction force vector $F_{r}$ can be obtained as:

$$
F_{r}=-C_{q}^{T} \lambda,
$$

When the constraint reaction force vector of the system is allocated according to the sequence of kinematic pairs and the number of rows of the constraint equation corresponding to the kinematic pairs, the restraint reaction force of a single kinematic pair on the rigid body can be obtained.

\subsection{Analytical Method of Carrier-Based Aircraft Catapult Variable Topology}

In the process of solving the catapult dynamics model of the carrier-based aircraft, the topological relationship of the system changes, and the dynamic equations should be adjusted accordingly. If the Kth motion pair constraint in the dynamic model needs to be removed, the corresponding row and column of the constraint condition should be removed from the dynamic equation, as shown in Figure 6. If a rigid body part in the dynamic model needs to be removed, it is not only necessary to remove the corresponding row and column of this part from the dynamic equation, but it is also necessary to remove all corresponding rows and columns of kinematic constraints related to this part from the dynamic equations, as shown in Figure 7.

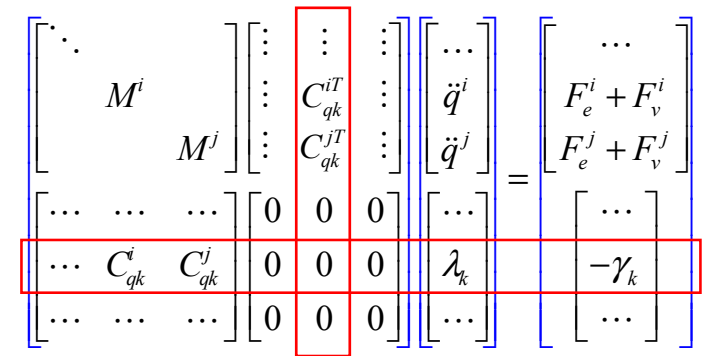

Figure 6. Method to remove constraints from the dynamic equations. 


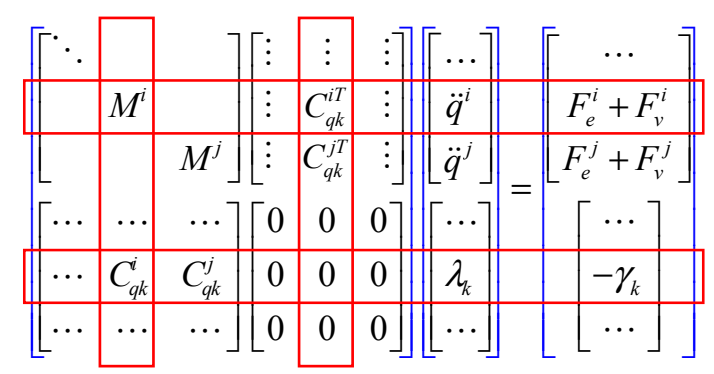

Figure 7. Rigid body removal method from the dynamic equations.

\section{Calculation Results of the Variable Topology of Carrier-Based Aircraft Catapult Dynamics}

Taking the catapult take-off of a carrier-based aircraft (Table 3) as an example, the dynamic response of the catapult of the modified aircraft is calculated by using the catapult dynamics model established in this paper.

Table 3. Catapult dynamics model parameters.

\begin{tabular}{cccc}
\hline Parameters & Numerical Values & Parameters & Numerical Values \\
\hline Take-off weight & $20,000 \mathrm{~kg}$ & Catapult heading overload & 2.5 \\
Engine thrust & $78.0 \mathrm{kN}$ & Restraint bar load threshold & $192.0 \mathrm{kN}$ \\
Catapult stroke & $90 \mathrm{~m}$ & & \\
\hline
\end{tabular}

Figure 8 shows the component variation curve of the restraint reaction force in the axis direction of the restraining rod at the joint of the restraining rod and the antitorsion arm of the nose gear, during the catapulting of the aircraft. After the catapulting starts, the load of the restraining rod increases rapidly, and at $0.123 \mathrm{~s}$, the curve appears at a breakpoint. The reason is that the restraint bar load reaches the design unlocking threshold $(192.0 \mathrm{kN})$ at $0.123 \mathrm{~s}$, which meets the restraint bar separation condition, then the system removes the restraint relationship between the restraining rod and the connection between the restraining rod component and the nose gear from the dynamic equation, and the subsequent calculation results no longer include the restraint reaction force at the joint of the restraining rod.

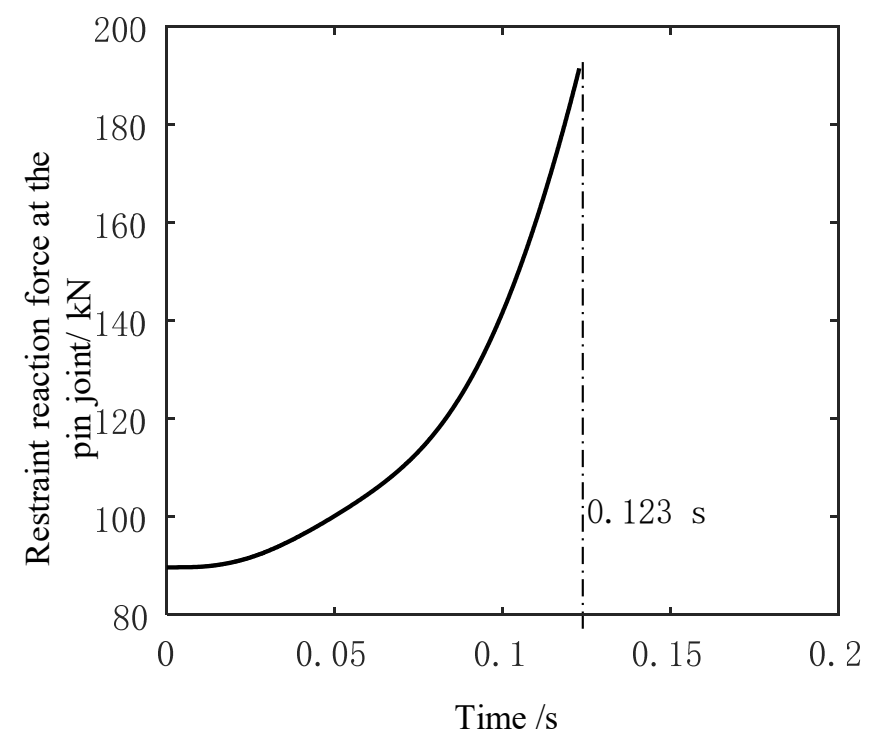

Figure 8. Time versus restraint reaction force at the pin joint. 
Figure 9 shows the component variation curve of the restraining reaction force at the joint of the catapult rod and the catapult trolley, in the direction of the catapult rod axis. At $2.867 \mathrm{~s}$, the load curve of the catapult rod has a breakpoint. The reason is that the catapult trolley reaches the end of the catapult stroke $(92 \mathrm{~m})$ at $2.867 \mathrm{~s}$, and the catapult rod is separated from the catapult trolley. The system removes the catapult trolley rod and the connection constraint relationship between the catapult trolley and the nose gear catapult rod from the dynamic equation, and the subsequent calculation results no longer include the constraint reaction force at the connection of the catapult rod and the catapult trolley.

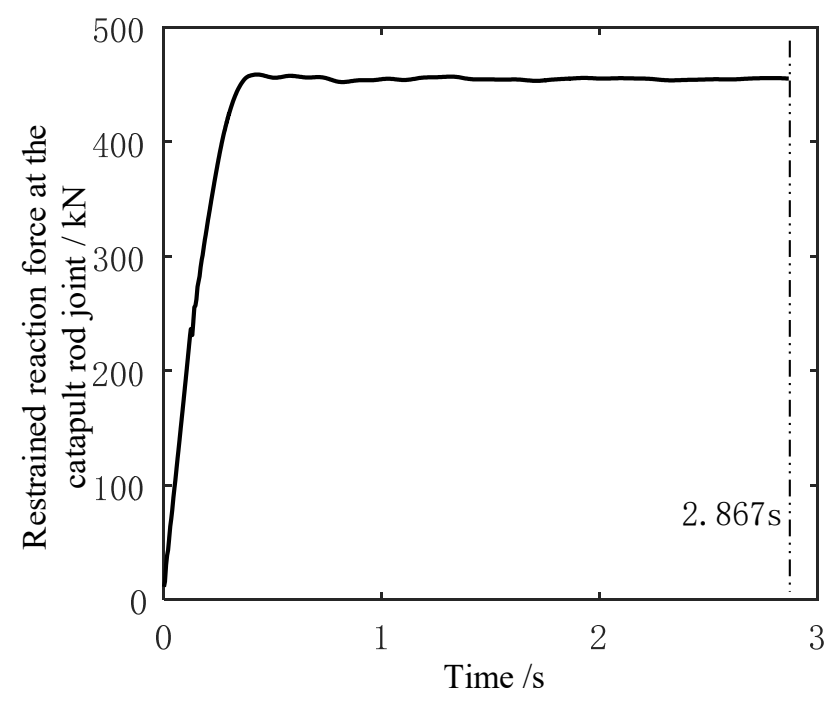

Figure 9. Time versus restrained reaction force at the catapult rod joint.

Figure 10 shows the change curve of the projected component of the restraining reaction force at the connection between the rear strut of the nose gear and the strut during the catapulting of the carrier-based aircraft. At $0.123 \mathrm{~s}$, due to the separation of the restraining rod and the front landing gear, the force transmission path of the front landing gear changes, and the catapult force is transmitted to the rear strut (Figure 2), causing the load of the rear strut to change from $-0.5 \mathrm{kN}$ to $238.0 \mathrm{kN}$. At $2.867 \mathrm{~s}$, due to the separation of the catapult rod and the catapult tackle, the catapult rod load disappears, and the load of the rear strut of the nose landing gear is reduced from $486.2 \mathrm{kN}$ to $-20.3 \mathrm{kN}$.

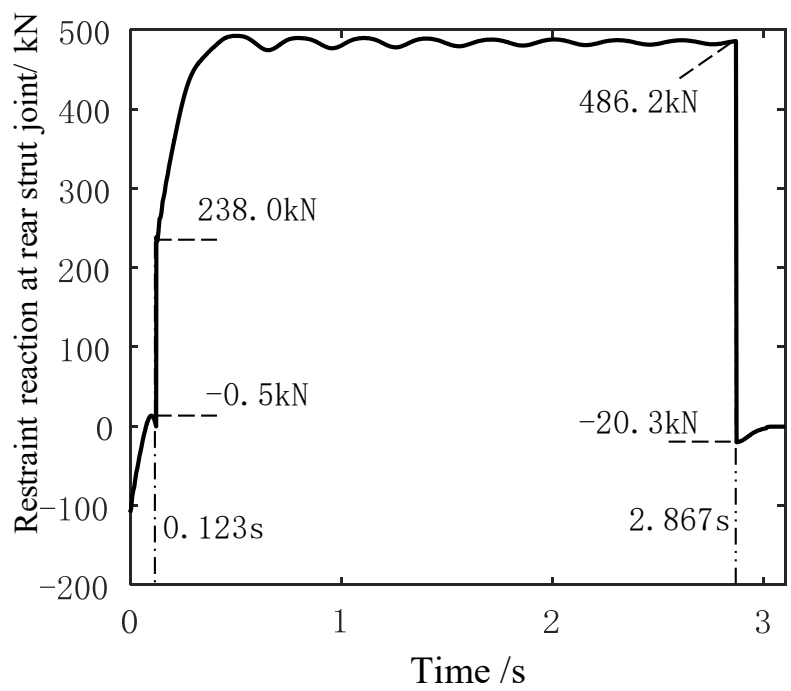

Figure 10. Time versus restrained reaction force at the catapult rod joint. 
Figure 11 shows the pitch angle change during the catapulting of the carrier-based aircraft. The aircraft is always dragged obliquely downward by the ejection rod, which leads to the pitch down moment of the aircraft in the process of dragging and sliding. As shown in Figure 11, the pitch angle ranges from $-1.61^{\circ}$ to $-0.64^{\circ}$. After the separation of the ejection rod and the shuttle, the pitch angle increases rapidly from $-0.93^{\circ}$ and reaches $0.54^{\circ}$ when the aircraft rushes out of the deck, which is mainly caused by the sudden extension of the nose landing gear.

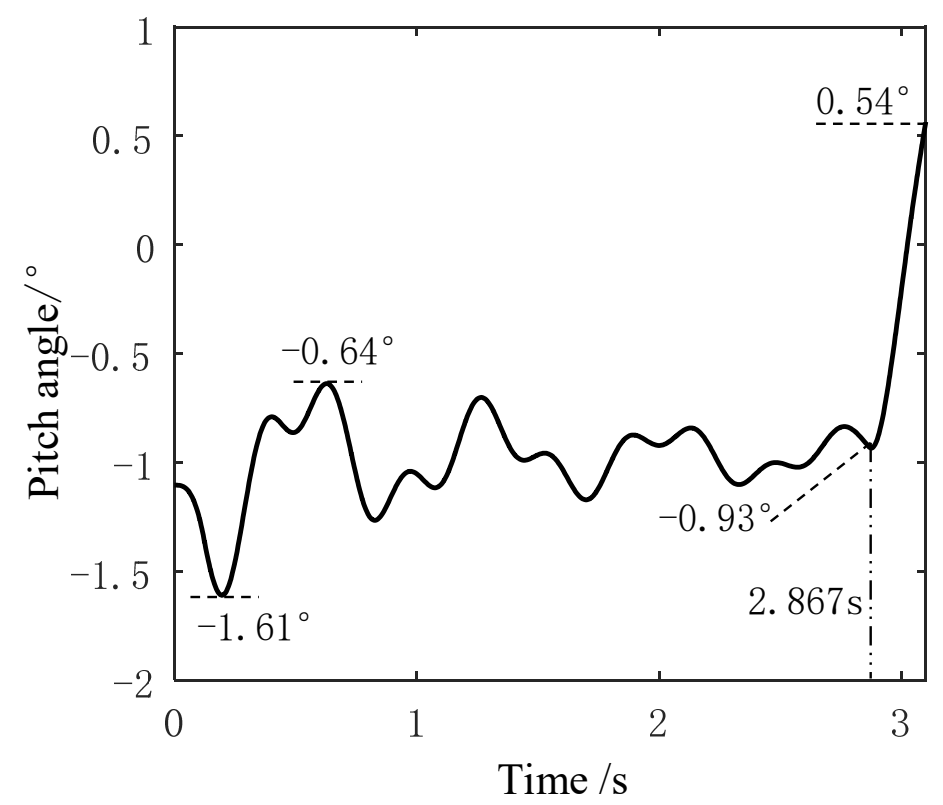

Figure 11. Time versus pitch angle of carrier-based aircraft.

\section{Conclusions}

In this paper, the catapult dynamics model of a carrier-based aircraft was established, and the dynamics model variable topology solution method was deduced. In addition, the dynamic calculation of the catapult and take-off process of a certain carrier-based aircraft was carried out, and the following conclusions were obtained:

(1) The catapult dynamics model and the variable topology solution method of the aircraft established in this paper can realize the variable topology solution of the separation of the restraining rod and the nose gear and the separation of the catapult rod and the catapult trolley during the catapulting process of the carrier-based aircraft.

(2) Before and after the tie rod and the nose gear were separated, due to the change in the force transmission path of the catapult load of the nose gear, the catapulting force was transmitted to the rear strut, which instantly increased the load of the rear strut by $238.5 \mathrm{kN}$.

(3) After the catapult started, the $2.867 \mathrm{~s}$ carrier aircraft reached the end of the catapult's stroke, the ejector rod was separated from the ejector tow shuttle, the ejector rod was unloaded, and the load of the rear strut was reduced from $486.2 \mathrm{kN}$ to $-20.3 \mathrm{kN}$.

(4) Due to the oblique downward traction of the catapult rod, the carrier-based aircraft was always in a state of bowing during the dragging and rolling process. After the catapult rod and the catapult tow shuttle were separated, the aircraft quickly turned into a head-up state under the protruding effect of the nose gear.

It is worth emphasizing that the methods and models adopted in this paper can be improved in terms of time cost and model accuracy. In future research, researchers could also use higher precision algorithms and more detailed models to analyze the dynamic response of the ejection and take-off processes. 
Author Contributions: Conceptualization, X.F. and H.C.; methodology, X.F.; software, H.C.; validation, H.N.; formal analysis, H.C.; investigation, H.C.; resources, X.F.; data curation, H.N.; writingoriginal draft preparation, H.C.; writing-review and editing, H.C.; visualization, H.C.; supervision, H.N.; project administration, H.N. All authors have read and agreed to the published version of the manuscript.

Funding: This research received no external funding.

Institutional Review Board Statement: Not applicable.

Informed Consent Statement: Not applicable.

Data Availability Statement: All data, models, and code generated or used during the study appear in the submitted article.

Conflicts of Interest: The authors declare no conflict of interest.

$\begin{array}{ll}\text { Nomenclature } \\ q & \text { Generalized coordinate array of the system } \\ M & \text { Generalized mass matrix } \\ N & \text { Number of mass matrices } \\ C_{q} & \text { System kinematics constraint matrix } \\ F_{v} & \text { Generalized coupled inertial force vector } \\ F_{e} & \text { Generalized active force vector } \\ \lambda & \text { Lagrangian multiplier } \\ F_{r} & \text { System constraint reaction force vector }\end{array}$

\section{References}

1. Small, D.B. Full Scale Tests of Nose Tow Catapulting: AIAA-1964-327; AIAA: Washingtong, DC, USA, 1964. Available online: https:/ / arc.aiaa.org/doi/pdf/10.2514/6.1964-327 (accessed on 26 September 2021).

2. Lucas, C. Catapult Criteria for a Carrier-Based Aircraft; Ltv Aerospace Corp Dallas Tex Vought Aeronautics DIV: Dallas, TX, USA, 1968. Available online: https:/ / apps.dtic.mil/sti/pdfs/AD0702814.pdf (accessed on 26 September 2021).

3. Ramsey, J.; Dixon, W. Carrier Suitability Tests of the Model A-6a Aircraft; Naval Air Test Center Technical Report: Maryland, USA, 1967. Available online: https://apps.dtic.mil/sti/pdfs/ADA382399.pdf (accessed on 26 September 2021).

4. Naval Air Engineering Center. Launching System, Nose Gear Type, Aircraft: MIL-L-22589D(AS); Naval Air Engineering Center: Lakehurst, NJ, USA, 1979. Available online: http:/ / everyspec.com/MIL-SPECS/MIL-SPECS-MIL-L/MIL-L-22589D_17610/ (accessed on 26 September 2021).

5. Naval Air Engineering Center. Tension Bar/Release Element, Aircraft Launching: MIL-T-23426D; Naval Air Engineering Center: Lakehurst, NJ, USA, 1986. Available online: http:/ / everyspec.com/MIL-SPECS/MIL-SPECS-MIL-T/MIL-T-23426D_53624/ (accessed on 26 September 2021).

6. Naval Air Engineering Center. Bar, Repeatable Release Holdback, Aircraft Launching, General Design Requirements for: MIL-B-85110(AS); Naval Air Engineering Center: Lakehurst, NJ, USA, 1997. Available online: http:/ / everyspec.com/MIL-SPECS/MIL-SPECSMIL-B/download.php?spec=MIL-B-85110.040474.pdf (accessed on 26 September 2021).

7. Naval Air Engineering Center. Airplane Strength and Rigidity Ground Loads for Navy Acquired Airplanes: MIL-A-8863C(AS); Naval Air Engineering Center: Lakehurst, NJ, USA, 1993. Available online: http:/ / everyspec.com/MIL-SPECS/MIL-SPECS-MIL-A/ MIL-A-8863C_10292/ (accessed on 26 September 2021).

8. Wang, W.; Qu, X.; Guo, L. Multi-agent based hierarchy simulation models of carrier-based aircraft catapult launch. Chin. J. Aeronaut. 2008, 21, 223-231. [CrossRef]

9. Jing, C.; Zhengchun, H. Research on dynamic modeling and correlative problems of catapult launch for carrier-based airplane. Flight Dyn. 2014, 32, 485-488. (In Chinese) [CrossRef]

10. Li, W.M.; Ma, X.L. Multi-body Dynamics Modeling and Catapult-launching Simulation for Carrier-based Aircraft. Mech. Sci. Technol. Aerosp. Eng. 2016, 35, 1797-1804. (In Chinese) [CrossRef]

11. Wang, J.Y.; Wu, W.H.; Gao, L.; Zhang, X.J. Modeling and Control of Carrier-based Airplane During Catapult Launch. Aircr. Design 2010, 30, 10-13. (In Chinese) [CrossRef]

12. Wei, X.H.; Liu, C.L.; Nie, H.; Zhang, M.; Yin, Q. Dynamics and Test Method of Carrier-based Aircraft Nose Landing Gear Sudden Extension. Acta Aeronaut. Astronaut. Sin. 2013, 34, 1363-1369. (In Chinese) [CrossRef]

13. Liu, C.C.; Cui, R.Y. Analysis and Test for Extension Performance of Nose Landing Gear of Carrier-based Aircraft. Mech. Sci. Technol. Aerosp. Eng. 2016, 35, 1686-1690. (In Chinese) [CrossRef]

14. Yu, H.; Nie, H.; Wei, X. Analysis on the dynamic characteristics of carrier-based aircraft nose landing gear with sudden holdback load discharge. Acta Aeronaut. Astronaut. Sin. 2011, 32, 1435-1444. (In Chinese) 
15. Xiaohui, W.; Liangliang, B.; Hong, N.; Ming, Z. Analysis on Anti-Vibration Holdback Device of Carrier-Based Aircraft. J. Nanjing Univ. Aeronaut. Astronaut. 2013, 45, 1-7. (In Chinese) [CrossRef]

16. Englebry, C.R. Impact of ramp launch technology on a navy support aircraft. J. Aircr. 1981, 18, 1003-1004. [CrossRef]

17. Imhof, G.; Schork, B. Using Simulation to Optimize Ski Jump Ramp Profiles for STOVL Aircraft; Naval Air Warfare Center Aircraft Division: Patuxent River, MD, USA, 1999. Available online: https://apps.dtic.mil/sti/pdfs/ADA378145.pdf (accessed on 26 September 2021).

18. Eppel, J.; Martin, J.; Hardy, G. Flight Investigation of the Use of a Nose Gear Jump Strut to Reduce Takeoff Ground Roll Distance of Stol Aircraft; National Aeronautics and Space Administration: Moffett Field, CA, USA, 1994. Available online: https://ntrs.nasa.gov/ api / citations/19950005812/downloads/19950005812.pdf (accessed on 26 September 2021). 